\title{
华北区域环境梯度上阔叶林构建模式及分布成因
}

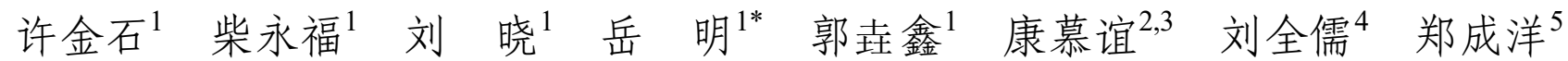 \\ 吉成均 ${ }^{5}$ 间 明 6 张 峰 ${ }^{7}$ 高贤明 ${ }^{8}$ 王仁卿 ${ }^{9}$ 石福臣 ${ }^{10}$ 张钦弟 ${ }^{6}$ 王 茂 1,11
}

${ }^{1}$ 西北大学西部资源生物与现代生物技术教育部重点实验室, 西安 710069; ${ }^{2}$ 北京师范大学地表过程与资源生态国家重点实验室, 北京 $100875 ;{ }^{3}$ 北京 师范大学地理科学学部自然资源学院, 北京 $100875 ;{ }^{4}$ 北京师范大学生命科学学院, 北京 $100875 ;{ }^{5}$ 北京大学城市与环境学院, 北京大学生态研究中心, 地表过程分析与模拟教育部重点实验室, 北京 $100871 ;{ }^{6}$ 山西师范大学生命科学学院, 山西临汾 $041000 ;{ }^{7}$ 山西大学黄土高原研究所, 太原 $030006 ;{ }^{8}$ 中 国科学院植物研究所植被与环境变化国家重点实验室, 北京 $100093 ;{ }^{9}$ 山东大学生命科学学院, 济南 $250100 ;{ }^{10}$ 南开大学生命科学学院, 天津 300071 ; ${ }^{11}$ 新疆农业大学草业与环境科学学院, 乌鲁木齐 830091

\begin{abstract}
摘 要 森林群落的构建即多样性维持机制是当今生态学研究的热点问题。然而, 当前群落构建和群落多样性的研究多在间 接梯度上进行, 而在水、热等影响物种在区域内定植的关键且直接的环境梯度上研究群落构建和多样性模式则鲜有报道。结 合环境因子, 基于物种组成和谱系方法探讨不同群落的分布成因, 有助于解释群落构建过程中的关键问题。该研究基于华北 森林群落调查数据和环境数据, 涉及 7 个省市区的 29 个以壳斗科、桦木科为优势种的群落, 探讨了直接环境梯度上的群落构建 和多样性模式, 同时用典范对应分析研究了不同群落分布的环境解释。结果发现, 相似的群落具有相似的生境偏好, 相似的 生境条件会形成物种组成相同或相似的群落。环境热量主导了本区域的谱系关系, 在年平均气温较低的地区, 群落构建主要 表现为生境过滤的模式。此外, 随着年降水量的增加, 生境过滤作用逐渐增加。在温度梯度上, 谱系多样性表现为钟形模式, 而降水量的增加能导致谱系多样性的增加。
\end{abstract}

关键词 群落构建; 谱系多样性; 水热条件; 物种组成

许金石, 柴永福, 刘晓, 岳明, 郭圭釒金, 康慕谊, 刘全儒, 郑成洋, 吉成均, 间明, 张峰, 高贤明, 王仁卿, 石福臣, 张钦弟, 王茂 (2019). 华北区域环境 梯度上阔叶林构建模式及分布成因. 植物生态学报, 43, 732-741. DOI: 10.17521/cjpe.2018.0183

\section{Community assembly, diversity patterns and distributions of broad-leaved forests in North China}

XU Jin-Shi ${ }^{1}$, CHAI Yong-Fu ${ }^{1}$, LIU Xiao ${ }^{1}$, YUE Ming ${ }^{1 *}$, GUO Yao-Xin ${ }^{1}$, KANG Mu-Yi ${ }^{2,3}$, LIU Quan-Ru ${ }^{4}$, ZHENG Cheng-Yang, ${ }^{5}$, J Cheng-Jun ${ }^{5}$, YAN Ming ${ }^{6}$, ZHANG Feng ${ }^{7}$, GAO Xian-Ming ${ }^{8}$, WANG Ren-Qing ${ }^{9}$, SHI Fu-Chen ${ }^{10}$, ZHANG Qin-Di ${ }^{6}$, and WANG Mao ${ }^{1,11}$

${ }^{1}$ Key Laboratory of Resource Biology and Biotechnology in Western China, Ministry of Education, Northwest University, Xi'an 710069, China; ${ }^{2}$ State Key Laboratory of Earth Surface Processes and Resource Ecology, Beijing Normal University, Beijing 100875, China; ${ }^{3}$ College of Resources Science \& Technology, Faculty of Geographical Science, Beijing Normal University, Beijing 100875, China; ${ }^{4}$ College of Life Sciences, Beijing Normal University, Beijing 100875, China; ${ }^{5}$ Institute of Ecology, College of Urban and Environmental Sciences, Laboratory for Earth Surface Processes of the Ministry of Education, Peking University, Beijing 100871, China; ${ }^{6}$ College of Life Sciences, Shanxi Normal University, Linfen, Shanxi 041000, China; ${ }^{7}$ Institute of Loess Plateau, Shanxi University, Taiyuan 030006, China; ${ }^{8}$ State Key Laboratory of Vegetation and Environmental Change, Institute of Botany, Chinese Academy of Sciences, Beijing 100093, China; ${ }^{9}$ School of Life Sciences, Shandong University, Jinan 250100, China; ${ }^{10}$ College of Life Sciences, Nankai University, Tianjin 300071, China; and ${ }^{11}$ College of Grass Industry and Environmental Science, Xinjiang Agricultural University, Ürümqi 830091, China

\footnotetext{
Abstract

Aims To understand the key processes driving the community assembly and diversity patterns in North China. Methods We investigated species composition of 87 plots from 29 sites. We applied phylogenetic approach, combined with community distribution information, to assess the community structure and diversity along environmental gradients. We then performed a variance partition to explore the relative importance of each environmental factor that influencing the patterns of community assembly and diversity process and a canonical correspondence analysis to analyze reason of community distributions.

Important findings Similar communities showed similar habitat preferences, demonstrating that environments may shape species composition of the communities. The phylogenetic diversity showed a uni-modal pattern with the mean annual temperature (MAT), but increased with the mean annual precipitation (MAP), partly because of the strong disturbance in high-MAT regions. Temperature dominated the phylogenetic structure of the broadleaved forests in North China. Environmental filtering dominate the community assembly processes in the areas

收稿日期Received: 2018-07-30 接受日期Accepted: 2018-11-17

基金项目：国家科技基础性工作专项(2011FY110300)、中国博士后科学基金(2018M643715)和国家自然科学基金(31700348)。Supported by the National Basic Work of Science and Technology of China (2011FY110300), the China Postdoctoral Science Foundation (2018M643715), and the Natural Science Foundation of China (31700348).

* 通信作者Corresponding author (yueming@nwu.edu.cn)
} 
with relatively low MAT. In addition, the effect of environment filtering increased with MAP.

Key words community assembly; phylogenetic diversity; hydrothermal condition; species composition

Xu JS, Chai YF, Liu X, Yue M, Guo YX, Kang MY, Liu QR, Zheng CY, Ji CJ, Yan M, Zhang F, Gao XM, Wang RQ, Shi FC, Zhang QD, Wang M (2019). Community assembly, diversity patterns and distributions of broad-leaved forests in North China. Chinese Journal of Plant Ecology, 43, 732-741. DOI: 10.17521/cjpe.2018.0183

群落构建即群落物种多样性的维持机制, 一直 是群落生态学的研究热点(Chase, 2003)。然而, 群落 构建的形式尚存在争论(宫贵权等, 2011)。目前, 基 于确定性过程的生态位理论和基于随机过程的中性 理论是最常用来检验群落构建模式的两个假说 (Kelly et al., 2008; Kylafis \& Loreau, 2011)。由于群 落构建过程中往往受到多种因子控制, 基于生态位 理论的环境过滤、竞争排除(Webb et al., 2002)与基 于中性理论的扩散限制(Wehncke et al., 2010)等作 用可能同时影响着群落构建。

群落内物种的多度反映了该物种在群落中的相 对重要性, 代表了该物种占有资源的能力 (Grime, 1998; 曹科等, 2013)。基于物种组成数据, 可以探究 相似物种组成的群落的分布模式。群落内的生物多 样性则与多种环境因子有关(Qian et al., 2014; 车应 弟等, 2017)。通过多样性分析, 可以探究群落内物 种形成、共存及时空变化规律(Swenson et al., 2012)。 因此, 研究环境因子与群落物种组成及多样性之间 的关系, 有助于预测多样性的动态(Yang \& Da, 2006; 周晓果等, 2014), 进而理解群落构建的过程。

群落内的物种组成是进化过程与生态过程共同 作用的结果(黄建雄等, 2010), 以群落内物种的亲缘 关系即谱系为载体进行群落构建研究, 能够较好地 从进化角度反映群落构建过程中的生态学机制 (Park \& Potter, 2015)。基于系统发育的谱系多样性 考虑了不同生物类群间的谱系关系及进化历史等信 息, 能够较好地从进化角度反映群落的多样性模式 (Cavender-Bares et al., 2009; 杨洁等, 2014), 并揭示 多样性维持机制(即群落构建过程)(Purschke et al., 2013; 贾鹏和杜国祯, 2014)。群落内物种可能因环 境过滤或竞争排除而使谱系聚集或发散, 从而表现 出特定的谱系结构(Webb, 2000; Swenson et al., 2012)。例如, 环境过滤作用主导群落构建时, 筛选 出的群落内物种亲缘关系可能较近, 从而适应当前 生境(卢孟孟等, 2014), 其谱系结构表现为聚集; 竞 争排除作用主导群落构建时, 亲缘关系较近的物种 无法占用相似的生态位(Wiens \& Graham, 2005), 从
而排除部分近缘种，其谱系结构表现为发散; 扩散 限制作用主导群落构建时, 群落的形成与环境因子 及生物间相互作用无关(Hubbell，2001)，其谱系结 构表现为随机(柴永福和岳明, 2016)。先前的许多研 究通过构建零模型来判断谱系结构的聚集与发散 (牛红玉等, 2011), 从而证明环境过滤、竞争排除或 扩散限制的存在，阐明不同作用在群落构建过程中 的相对重要性(Foster et al., 2004; Cavender-Bares et al., 2009; Mayfield \& Levine, 2010; 姜晓燕等, 2016)。基于此方法, 先前的研究认为, 环境因子造 成的环境过滤往往主导了构建过程(Huang et al., 2014), 尤其在生境条件比较苛刻的地区，如高海拔 区域(Mori et al., 2013; Xu et al., 2017; 赵鸣飞等, 2017)。然而, 海拔毕竟是一个间接化的生境因子, 其与温度、降水、紫外辐射强度、风速、土壤养分 等诸多因子相关(Xu et al., 2018)。探讨单一的水热 梯度上群落构建的变化模式, 能够更清晰地阐明群 落与水热因子的关系, 从而明确区域尺度上群落的 构建模式。然而, 这方面的研究却鲜有报道。

在较大的空间尺度上基于水热梯度进行物种组 成、构建机制的研究，有助于分析区域尺度内的物 种多样性及其分布规律, 理解本区域内水热条件与 森林类型间的耦合关系。本研究基于华北群落调查 数据及环境数据构建本区域的生境梯度, 拟通过分 析群落内物种组成及系统发育结构等手段, 分析华 北区域环境梯度上温带典型落叶阔叶林在水热梯度 上物种组成、谱系多样性和谱系结构的变化规律, 试图回答以下问题: 1)相似的环境条件是否会发育 相似的森林群落? 2)在本区域内水/热是否驱动物 种组成或群落构建模式变化? 如何变化? 通过研究 及解释这些问题，可为相似生态区域内植被恢复、 森林保护和林业生产提供有效的理论支持。

\section{1 材料和方法}

\section{1 研究地点}

本研究的研究地点全部位于广义华北区域, 涉 及河北、河南、山西、陕西、天津、山东、宁夏等7 
个省市自治区。研究区域内有太行山脉、秦岭山脉、 燕山山脉及华北平原、黄土高原等地理单元, 地形 复杂多样, 海拔范围350-2 500 m。受调查地点海拔 和经纬度的影响, 研究区域内样方年平均气温和年 降水量变化很大, 具体样方及环境信息见表 1 。从以 下研究地点中, 选择了优势种属于壳斗科和桦木科 的森林群落作为本研究的研究对象, 这些森林群落 的优势种有辽东栎(Quercus wutaishanica)、栓皮柇 (Q. variabilis)、麻栎 $(Q$. acutissima)、锐齿檞栎 $(Q$. aliena var. acuteserrata)、蒙栋(Q. mongolica)、白桦 (Betula platyphylla)、红桦(B. albosinensis)、粘皮华 (B. utilis)、鹅耳枥(Carpinus turczaninowii)、千金榆
(C. cordata $)$ 等。

\section{2 野外调查方法}

2011-2015年, 在29个样地展开群落调查, 每个 样地按优势种群落布置 3 个 $30 \mathrm{~m} \times 20 \mathrm{~m}$ 的森林样方, 共计布置 87 个样方。记录样方内胸径 $(D B H) \geqslant 3 \mathrm{~cm}$ 的 木本植物的种名、多度、盖度、胸径、高度。此外, 记 录每个样方的经纬度、海拔、坡度、坡位、坡向等 地理因子。共调查物种 234 个, 详见附录 $\mathrm{I}$ 。

\section{3 环境数据}

除野外调查记录的地理因子数据外, 根据样方 经纬度, 在WorldClim数据库(http://www.worldclim. org/)中提取了 $5 \mathrm{~km} \times 5 \mathrm{~km}$ 网格化地图的其他环境

表1 华北区域阔叶林样地信息

Table 1 Information of study sites of broad-leaved forests in North China

\begin{tabular}{|c|c|c|c|c|c|}
\hline $\begin{array}{l}\text { 样地 } \\
\text { Site }\end{array}$ & $\begin{array}{l}\text { 群落类型 } \\
\text { Community type }\end{array}$ & $\begin{array}{l}\text { 地点 } \\
\text { Site }\end{array}$ & $\begin{array}{c}\text { 平均海拔 } \\
\text { Mean elevation (m) }\end{array}$ & $\begin{array}{c}\text { 年平均气温 } \\
\operatorname{MAT}\left({ }^{\circ} \mathrm{C}\right)\end{array}$ & $\begin{array}{l}\text { 年降水量 } \\
M A P(\mathrm{~mm})\end{array}$ \\
\hline JLQ & 蒙栎林 Quercus mongolica forest & 河北隆化 Longhua, Hebei & 1085 & 5.5 & 466 \\
\hline JWA & 红桦林 Betula albosinensis forest & 河北溷鹿 Zhuolu, Hebei & 2302 & -0.8 & 624 \\
\hline JFL & 辽东栋林 Quercus wutaishanica forest & 河北阜平 Fuping, Hebei & 1550 & 4.4 & 513 \\
\hline JFE & 鹅耳枥林 Carpinus turczaninowii forest & 河北阜平 Fuping, Hebei & 1517 & 4.4 & 513 \\
\hline JLB & 白桦林 Betula platyphylla forest & 河北涞源 Laiyuan, Hebei & 1819 & 7.1 & 491 \\
\hline JSC & 楉皮桦林 Betula utilis forest & 河北灵寿 Lingshou, Hebei & 1693 & 4.1 & 527 \\
\hline YWS & 栓皮栋林 Quercus variabilis forest & 河南卫辉 Weihui, Henan & 371 & 13.8 & 593 \\
\hline NGB & 白桦林 Betula platyphylla forest & 宁夏固原 Guyuan, Ningxia & 2370 & 4.2 & 591 \\
\hline QFL & 辽东栋林 Quercus wutaishanica forest & 陕西富县 Fu Xian, Shaanxi & 1166 & 9.4 & 527 \\
\hline LTM & 麻栋林 Quercus acutissima forest & 山东泰安 Tai’an, Shandong & 516 & 10.1 & 833 \\
\hline LPS & 栓皮栋林 Quercus variabilis forest & 山东平邑 Pingyi, Shandong & 557 & 12.3 & 805 \\
\hline SZL & 辽东栋林 Quercus wutaishanica forest & 山西左权 Zuoquan, Shanxi & 1896 & 5.0 & 636 \\
\hline $\mathrm{SCL}$ & 辽东栋林 Quercus wutaishanica forest & 山西陵川 Lingchuan, Shanxi & 1093 & 9.0 & 703 \\
\hline SQA & 红桦林 Betula albosinensis forest & 山西沁水 Qinshui, Shanxi & 2170 & 5.4 & 731 \\
\hline SLE & 鹅耳枥林 Carpinus turczaninowii forest & 山西临县 Lin Xian, Shanxi & 1038 & 8.3 & 595 \\
\hline SLS & 栓皮栋林 Quercus variabilis forest & 山西临县 Lin Xian, Shanxi & 1077 & 8.3 & 595 \\
\hline SQE & 鹅耳枥林 Carpinus turczaninowii forest & 山西沁水 Qinshui, Shanxi & 1344 & 9.2 & 635 \\
\hline SQB & 白桦林 Betula platyphylla forest & 山西沁水 Qinshui, Shanxi & 1638 & 7.7 & 673 \\
\hline SYS & 栓皮栋林 Quercus variabilis forest & 山西垣曲 Yuanqu, Shanxi & 872 & 11.1 & 584 \\
\hline SSJ & 千金榆林 Carpinus cordata forest & 山西灵石 Lingshi, Shanxi & 1288 & 6.7 & 578 \\
\hline $\mathrm{SJL}$ & 辽东栋林 Quercus wutaishanica forest & 山西交城 Jiaocheng, Shanxi & 1731 & 4.9 & 518 \\
\hline SQL & 辽东栋林 Quercus wutaishanica forest & 山西沁水 Qinshui, Shanxi & 1140 & 9.8 & 623 \\
\hline YSS & 栓皮栋林 Quercus variabilis forest & 河南嵩县 Song Xian, Henan & 1099 & 9.4 & 778 \\
\hline YTR & 锐齿葪栋林 Quercus aliena var. acuteserrata forest & 河南桐柏 Tongbai, Henan & 817 & 12.9 & 1011 \\
\hline YXS & 栓皮栋林 Quercus variabilis forest & 河南信阳 Xinyang, Henan & 155 & 15.4 & 1077 \\
\hline YGS & 栓皮栋林 Quercus variabilis forest & 河南舞钢 Wugang, Henan & 132 & 14.8 & 784 \\
\hline YYM & 麻栋林 Quercus acutissima forest & 河南驻马店 Zhumadian, Henan & 124 & 14.8 & 840 \\
\hline YNR & 锐齿葪栋林 Quercus aliena var. acuteserrata forest & 河南内乡 Neixiang, Henan & 1369 & 8.9 & 917 \\
\hline TJS & 栓皮栋林 Quercus variabilis forest & 天津蓟县 Ji Xian, Tianjin & 193 & 10.1 & 590 \\
\hline
\end{tabular}

MAT, mean annual temperature; $M A P$, mean annual precipitation.

www.plant-ecology.com 
因子, 包含年平均气温、月平均气温极差、等温性、 气温季节变化率、最暖月最高气温、最冷月最低气 温、年气温变化值、最湿季平均气温、最干季平均 气温、最暖季平均气温、最冷季平均气温、年降水 量、最湿月降水量、最干月降水量、降水季节变化 量、最湿季降水量、最干季降水量、最暖季降水量、 最冷季降水量等 19 个水热因子。以上数据通过 $\mathrm{R}$ 3.1.1软件的“raster”程序包获得。

\section{4 数据分析}

为探讨物种组成相同(或相似)群落是否具有生 境选择的一致性偏好, 采用典范对应分析(CCA)对 环境因子进行进一步降维, 并对环境-物种关系进 行解析。CCA及制图在Canoco 4.5 软件中进行。

为分析样方的谱系结构和谱系多样性, 需要构 建谱系树。将附录I中的物种作为骨架, 基于APGIII 系统, 使用在线工具Phylomatic构建研究区域的超 级谱系树(Webb \& Donohue, 2005)。在Phylocom 3.0 软件中, 将所构建的超级谱系树用BLADJ方法拟合 物种的进化枝长(Wikström et al., 2001)。带有进化枝 长的超级谱系树即为构建零模型所用的本底数据。 在Phylocom 3.0软件中运用COMSTRUCT模块计算 净种间亲缘关系指数 $(N R I)$ 和净最近种间亲缘关系 指数(NTI) 代表谱系结构, 计算运行999次。NRI和 $N T I$ 的具体计算方法如下:

$$
\begin{aligned}
& N R I_{\mathrm{s}}=-1 \times \frac{M P D_{\mathrm{s}}-M P D_{\mathrm{mds}}}{S D\left(M P D_{\mathrm{mds}}\right)} \\
& N T I_{\mathrm{s}}=-1 \times \frac{M N T D_{\mathrm{s}}-M N T D_{\mathrm{mds}}}{S D\left(M P D_{\mathrm{mds}}\right)}
\end{aligned}
$$

式中, $M P D$ 与 $M N T D$ 为样方物种平均谱系距离和平 均最近相邻谱系距离(Kraft et al., 2007), 下角标 $\mathrm{S}$ 代 表实际观察值, $m d s$ 代表软件的随机模拟值, $S D$ 为其 标准偏差。NRI $/ N T I>0$, 谱系聚集; $N R I / N T I<0$, 谱 系发散; NRI $/ N T I=0$, 谱系随机(Kraft et al., 2007)。

谱系多样性用Faith's PD (Faith, 1992)描述。 Faith's PD用Phylocom 3.0中的PD模块计算。Faith's $\mathrm{PD}$ 计算的是群落内所有物种的进化枝总长。

为探究环境尤其是水热梯度是否影响群落谱系 结构、谱系多样性和物种组成, 用方差分解法计算 环境因子对群落 $M P D$ 变化的解释程度。为避免多重 共线性的影响, 在进行方差分解前, 用SPSS 19.0软 件对参与分析的环境因子进行了多重共线性检验, 最终选取了年平均气温、年降水量、月平均气温极
差、降水季节变化量、坡度和坡向作为参与分析的 环境因子。根据方差分解的结果, 即可得出影响研 究区域内样方谱系关系的主要环境因子, 并将主要 环境因子与群落的谱系结构、谱系多样性指标做了 拟合。在拟合过程中, 我们也区分了不同森林类型 (表1), 拟探讨不同森林类型的群落谱系变化。但由 于桦木科为主的森林群落样本数较少, 其涉及的梯 度区间也有限, 在分析过程中与壳斗科为主的群落 相比并未表现出明显的、有统计学意义的差异, 结 果中未予显示。方差分解在 R 3.1.1 软件下基于 “hier.part”程序包完成, 拟合与 ANOVA分析在 Origin 8.0软件中完成。

\section{2 结果}

\section{1 群落类型与环境的关系}

CCA 1 轴能解释环境和物种总变化的 $27.3 \%$, CCA 2轴能解释环境和物种总变化的 $20.5 \%, \mathrm{CCA}$ 前 两轴能解释环境和物种总变化的 $47.8 \%$ 。 $\mathrm{CCA}$ 的 1 轴 与 2 轴均与年降水量 $(M A P)$ 、月平均气温极差 $(M M T D)$ 、平均气温 $(M A T)$ 及降水季节变化量 $(S V P)$ 有关, 但坡度(Slope)只与 CCA 2轴有关(附录II)。因 此, $\mathrm{CCA}$ 的 1 轴和 2 轴可以看作综合的环境变量。在 进行群落分析时, 我们选择了样方数较多的辽东 栋、栓皮柇群落作为壳斗科物种为优势种森林的代 表群落; 选择了白桦和鹅耳枥群落作为桦木科物 种为优势种森林的代表群落。群落的CCA结果见图 1 。对于壳斗科物种为优势种的群落, 辽东柇林基 本落在 CCA 1 轴的负半轴上, 栓皮柇林基本落在 CCA 1 轴的正半轴上。壳斗科物种为优势种的群落 在 4 个象限均有分布。对于桦木科物种为优势种的 群落, 白桦与我耳枥林均基本落在 CCA 1 轴的负半 轴上, 且其在几个象限中的分布比柇林局限。其他 的桦木科物种为优势种的群落全部分布在第二象 限(图1)。

\section{2 影响区域内样方内谱系关系的主要环境因子}

基于方差分解结果(表2), MAT能够解释 $M P D$ 变 化的 $48.04 \%$, 是影响区域内样方内谱系关系的最主 要环境因子。 $M M T D$ 能够解释 $M P D$ 变化的 $16.43 \%$ 。 此外, 坡向和 $M A P$ 也在一定程度上影响了样方内物 种的谱系关系。由于 MMTD与 $M A P$ 相关性较强 (Pearson系数 $=0.801, p<0.01$ ), 因此, 接下来的分 析中, 重点讨论MAT和MAP梯度, 即水热梯度。 


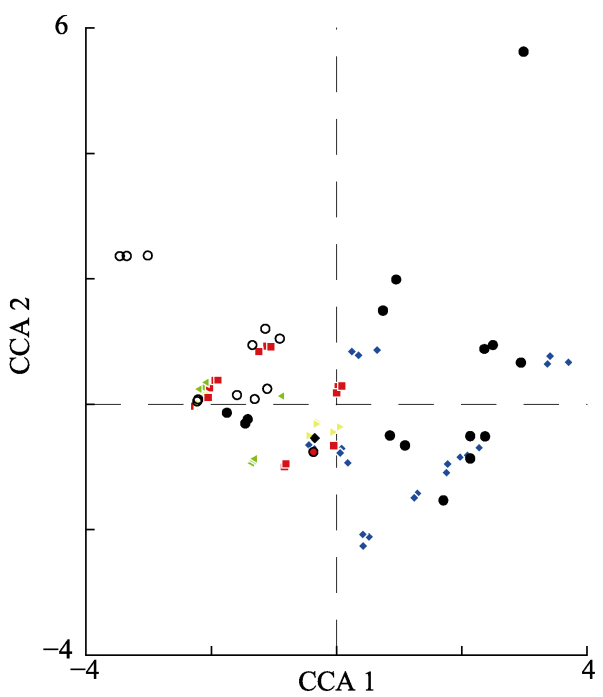

- 辽东栋林 Quercus wutaishanica Forest

- 检皮柇林 $Q$. variabilis Forest

4 白桦林 Betula platyphylla Forest

鹅耳栖林 Carpinus turczaninowii Forest

- 其他壳斗科优势群落 Other Fagaceae dominant communities

○ 其他桦木科优势群落 Other Betulaceae dominant communities

图1 华北地区阔叶林样方物种组成变化的典范对应分析 (CCA)结果。

Fig. 1 Result of canonical correspondence analysis (CCA) of species composition among plots of broad-leaved forests in North China.

表2 华北地区阔叶林环境因子对样方平均谱系距离(MPD)的方差分解 结果

Table 2 Result of variance decomposition of environment factors to mean phylogenetic distance (MPD) of broad-leaved forests in North China

\begin{tabular}{lc}
\hline 环境因子 Factor & 解释程度 \\
\hline 坡度 Slope & 3.2003 \\
坡向 Aspect & 15.6437 \\
年平均气温 $M A T$ & 48.0438 \\
月平均气温极差 $M M T D$ & 16.4336 \\
年降水量 $M A P$ & 15.0653 \\
降水季节变化量 SVP & 1.6132
\end{tabular}

MAP, mean annual precipitation; MAT, mean annual temperature; MMTD, mean month temperature difference; $S V P$, seasonal variation of precipitation.

\section{3 水热梯度上群落谱系结构模式}

通过回归分析，明确了在 $M A T$ 和 $M A P$ 梯度上 $N R I$ 和 $N T I$ 的变化。结果见图2、图3。

由图2可知, $N R I$ 与 $N T I$ 在 MAT梯度上表现相似。 在整个研究区域内, 大多数的样方表现出了谱系聚 集的模式。随 $M A T$ 的升高, NRI和 NTI都基本表现出 由聚集到随机的趋势，且 $N R I$ 的趋势更加明显。然而， 在MAP梯度上, NTI和NRI的表现模式有所差异。随 $M A P$ 的增加, $N T I$ 表现出逐渐聚集的模式, 而 $N R I$ 的 变化不大(图3)。

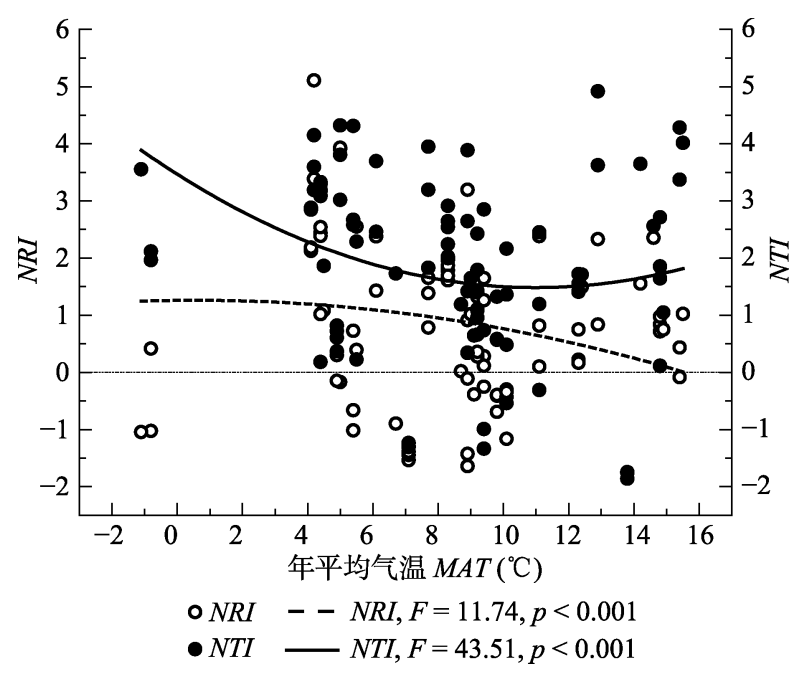

图2 华北地区阔叶林谱系结构与年平均气温的关系。 $N R I$, 净种间亲缘关系指数; NTI, 净最近种间亲缘关系指数。0值 上的点状线为 0 预期的谱系结构。

Fig. 2 Pattern of the relationship between phylogenetic structure and mean annual temperature (MAT) of broad-leaved forests in North China. NRI, net relatedness index; NTI, nearest taxon index. The dotted line on 0 represented null expectation of phylogenetic structure.

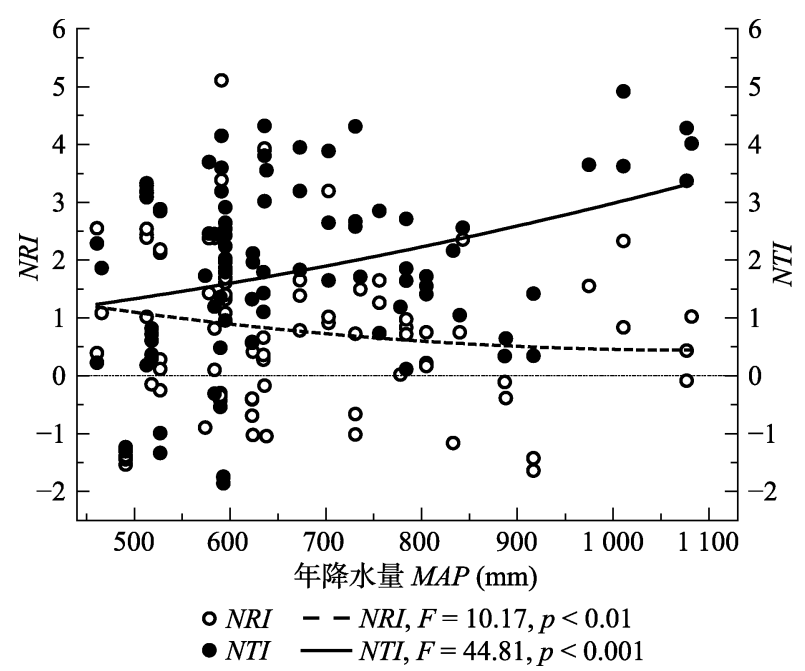

图3 华北地区阔叶林谱系结构与年降水量的关系。虚线为 $N R I$ 的拟合线，实线为 $N T I$ 的拟合线。 0 值上的点状线为 0 预期 的谱系结构。

Fig. 3 Pattern of the relationship between phylogenetic structure and mean annual precipitation (MAP) of broad-leaved forests in North China. The dotted line on 0 represented null expectation of phylogenetic structure.

\section{4 水热梯度上的谱系多样性模式}

Faith's PD随MAT的上升，表现出开口向下的抛 物线模式, 其顶点在 $10{ }^{\circ} \mathrm{C}$ 左右。即在年平均气温较 低和较高的区域, 群落谱系多样性较低, 而MAT在

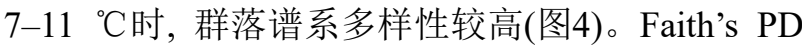
在 $M A P$ 梯度上表现出单调上升的趋势(图5), 即随着 $M A P$ 的增加，群落的谱系多样性也增加。 


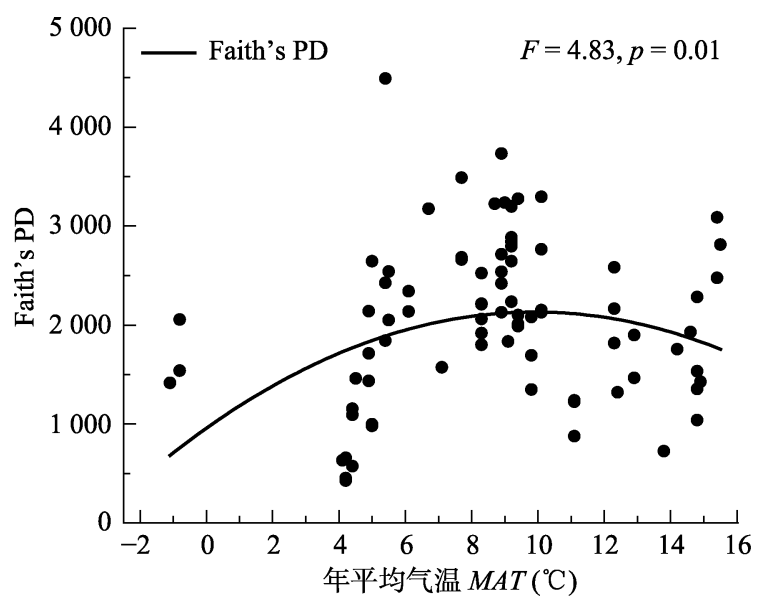

图4 华北地区阔叶林谱系多样性指数(Faith's PD)与年平均 气温的关系。图中的黑点为样方的Faith's PD值, 实线为谱系 多样性的拟合线。

Fig. 4 Pattern of the relationship between phylogenetic diversity (Faith's PD) and mean annual temperature (MAT). Solid circles represent the value of Faith's PD. The solid curve represent regression curve of phylogenetic diversity.

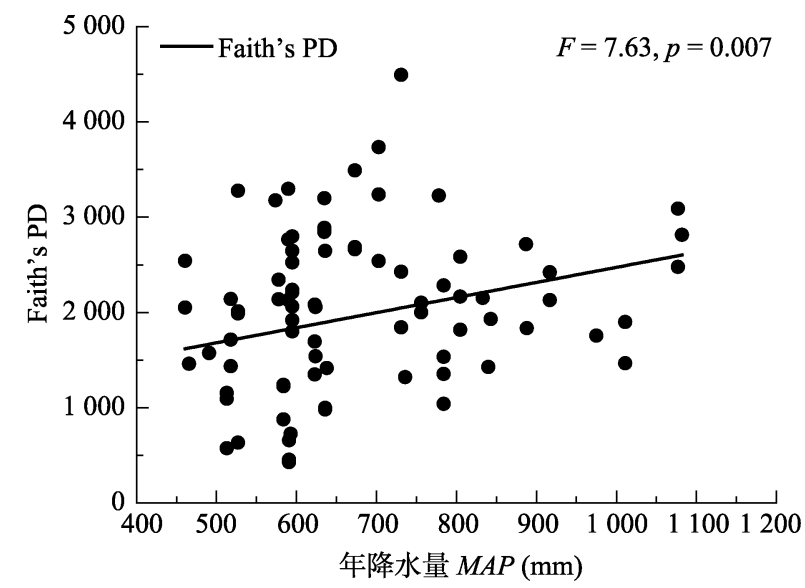

图5 华北地区阔叶林谱系多样性指数(Faith's PD)与年降水 量的关系。图中的黑点为样方的Faith's PD值, 实线为谱系多 样性的拟合线。

Fig. 5 Pattern of the relationship between phylogenetic diversity (Faith's PD) and mean annual precipitation (MAP). Solid circles represent the value of Faith's PD. The solid line represent regression curve of phylogenetic diversity.

\section{3 讨论}

\section{1 华北区域内相似的阔叶林群落具有相似的生} 态条件

群落构建研究的主要目的之一就是要回答是否 在相似的生境条件下会形成相似的群落。Chase (2003)认为, 即使在相似的环境下, 由于优先效应 的存在, 其物种组成也是不一致的。因此, 探究相似 的群落物种组成是否具有相似的生境条件, 也是当 今生态学研究的主要焦点之一。在本研究中, 基于
$\mathrm{CCA}$ ，可以探索相同或相似的群落是否具有相似的 环境条件。例如，在较大的层面上，以壳斗科物种为 优势种的森林群落比以桦木科为优势种的森林群落 的生态幅更宽(图1), 可以适应更宽范围的生境条件, 而以华木科物种为优势种的森林群落局限于第二、 三象限。其中，红华、䊁皮桦和千金榆(图1中的白 色圆圈)等物种仅局限于第二象限, 而第二象限与 低温、低降水量、高温差、大坡度等生境条件有关, 这些条件正是较高的山地中具有的生态条件。因此, 以桦木科为优势种的群落的生态幅是较窄的, 只能 出现在特定的生境中。

在较小的层面上, 以同一科属下不同物种为优 势种的森林群落的分布范围也有差别。例如, 辽东 栋和栓皮栋也有各自的生态偏好。在图1中, 辽东栎 与栓皮栎的分布范围重叠非常小, 说明二者具有比 较明显的分布生态界限, 占用着不同的生态位(袁 秀等, 2011)。而同一优势种的森林群落之间则具有 明显的环境聚集模式。因此, 相同或相似物种组成 的群落, 其分布地的生态条件是相似的。

\section{2 热量是影响华北区域阔叶林群落构建的主要 因素}

热量与水分条件是驱动群落构建的最主要、最 直接的因素(Xu et al., 2018)。前人对于群落构建的 研究发现, 海拔和纬度能够驱动群落构建(Qiao et al., 2015; Xu et al., 2017), 是因为海拔与纬度同热 量条件呈明显的负相关关系(唐志尧等, 2004)。在本 研究区域内, 由于纬度跨度大, MAT也有很大差异。 因此, 海拔和纬度同时影响了研究样地的 $M A T$ 。本 研究发现, 造成华北区域内阔叶林群落谱系关系变 化的主要因子是 $M A T$, 且还与 $M M T D$ 有关(表2)。对 $N R I 、 N T I$ 及 $P D$ 与 $M A T$ 的显著拟合回归结果也证明了 这一点(图2, 图4)。另外, 谱系变化还与坡向有关(表 2), 而坡向的差异正是导致群落热量差异的因素之 一。因此, 热量是影响华北区域阔叶林群落构建的 最主要因素。除此之外, 水分(如本研究中的 $M A P$ ) 也在较大程度上影响着群落构建的过程(表2)。

\section{3 华北区域阔叶林群落水热梯度上的群落构建} 模式

单纯从水热梯度上进行群落构建研究的报道较 少, 然而, 有大量的基于经纬度、海拔等地理因子梯 度研究群落构建模式的报道。由于海拔与经纬度等 
信息中均包含了水热因素, 因此本研究可与这些研 究做类比。例如, 大部分研究发现, 高海拔(意味着 较低的温度, 由于凝冻, 也有较低的水分可用性)区 域主要受到环境过滤的作用, 而低海拔(意味着较 高的温度)区域则可以表现出中性或竞争排除的作 用(Hulshof et al., 2013; Mori et al., 2013; Pottier et al., 2013; Xu et al., 2017); 而高纬度(意味着较低的 温度、较少的降水) 区域的构建模式应该是聚集的 (Hodkinson et al., 2003)。然而, 也有部分研究得出 了不一致的结论, 例如, Zhang等(2013)发现, 亚高 山草甸的群落构建模式与海拔等非生物因素无关, 而卢孟孟等(2014)发现, 哀牢山干热河谷的群落的 谱系结构在高海拔区域趋于发散, 即在温度较低、 水分可用性也较低的区域并未受到环境过滤的 作用。

本研究发现, 在MAT梯度上, 群落的谱系结构 逐渐由聚集转向随机, 表明受到的环境过滤作用随 MAT的增加而逐渐降低。这说明, 温度是主导华北 区域内温度较低地区群落构建过程的主要生境因 子。在这些地区, 由于MAT较低, 有效积温不足, 严 酷的环境只能篎选出适应该低温条件的物种, 从而 表现出环境过滤作用。值得注意的是, 在MAT较高 的地区, 倾向于随机的构建模式并不一定是由扩散 限制等中性作用导致的, 也可能是由与之相反的非 中性作用叠加的结果(Mayfield \& Levine, 2010; 房 帅等, 2014)。

然而, 在 $M A P$ 梯度上, NRI和NTI所表现出的变 化模式不同, 这与前人得出的 $N R I$ 与 $N T I$ 表现模式不 符(Swenson et al., 2007), 但也说明了二者的适用范 围和敏感程度不一致, 有必要分别进行研究(Tucker et al., 2017)。由于 $N R I$ 的取值均未达到与零模型有显 著差异的水平, $N R I$ 在 $M A P$ 梯度上并未表现出明显 的变化趋势; 而NTI则随 $M A P$ 的增加表现出聚集的 趋势, 表明受到了环境过滤的作用。一般而言, MAP 较高的区域, 纬度更低, 更接近海岸, 且可能有较 低的海拔。就本研究而言, $M A P$ 最高的几个样地位 于河南、山东等省海拔较低的地区(表1), 而海拔较 低的区域往往有更严重的人为扰动(Xu et al., 2018), 从而导致这些样地内的环境条件较差(Lessard et al., 2009), 使群落受到环境过滤的作用。

\section{4 华北区域阔叶林群落谱系多样性的水热格局}

在本研究中, 谱系多样性在水热梯度上表现出
了不一致的模式。一般而言, 在温度梯度上, 随着样 方可用热量的上升，谱系多样性一般表现为上升的 模式(Qiao et al., 2015)。然而, 本研究中谱系多样性 最高的点落在 $M A T \approx 10{ }^{\circ} \mathrm{C}$ 的区域, 之后随着 $M A T$ 的上升, 谱系多样性又呈现下降的趋势(图3)。参照 表1, 本研究中 MAT $>10{ }^{\circ} \mathrm{C}$ 的样地中的群落无一例 外是本区域的顶极群落柇林, 而之前的研究已经发 现, 随着演替向顶极群落的进行, 群落中的多样性 水平逐渐降低(Chai et al., 2016), 因此, 本区域内 MAT较高地区多样性水平的下降也可由此解释。在 本研究中, 谱系多样性随MAP升高, 表明在华北区 域, 水分仍是导致群落内多样性水平变化的重要 因子。

\section{4 结论}

本研究基于环境梯度上物种组成、谱系结构和 谱系多样性的变化, 探究了华北区域直接环境梯度 上群落构建的模式及群落的形成原因。研究发现, 相似的生境条件可以形成相似的群落。MAT与 $M A P$ 是导致华北区域群落谱系变化的主要因子。在水热 梯度上的研究发现, 在华北区域内, 生境过滤是木 本植物群落构建的主要驱动过程。此外, MAT和 $M A P$ 均能影响华北区域的群落谱系多样性。在环境 梯度上基于物种、谱系进行群落构建和多样性变化 研究, 有助于为华北区域植被恢复和人工林营造提 供理论依据。

致谢 感谢北京师范大学赵鸣飞、薛峰、杨容、王 国义、问瑞亚, 西北大学陈显、党晗、万鹏程, 山西 大学苗艳明、卫晶、白聪、秦浩、邓永利、黄种乾、 苏智娇、王烨、秦晓娟、毛空、丁涁、董刚、刘莹、 刘海强, 山东大学张文馨、陈贻海、谭向峰、朱连 金、袁义福、罗玉洁、蔡云飞、卢鹏林、张月强, 中 国科学院植物研究所王玉兰、李连昌、赵国明、王 柄炎, 北京大学程绍卧、许丙青、姚贺帮, 南开大学 丛明旸、陈国平、赵瑞瑞、宫乐等的艰辛劳动。

\section{参考文献}

Cao K, Rao MD, Yu JP, Liu XJ, Mi XC, Chen JH (2013). The phylogenetic signal of functional traits and their effects on community structure in an evergreen broad-leaved forest. Biodiversity Science, 21, 564-571. [曹科, 饶米德, 余建 平, 刘晓娟, 米湘成, 陈建华 (2013). 古田山木本植物

www.plant-ecology.com 
功能性状的系统发育信号及其对群落结构的影响. 生 物多样性, 21, 564-571.]

Cavender-Bares J, Kozak KH, Fine PVA, Kembel SW (2009). The merging of community ecology and phylogenetic biology. Ecology Letters, 12, 693-715.

Chai YF, Yue M, Liu X, Guo YX, Wang M, Xu JS, Zhang CG, Chen Y, Zhang LX, Zhang RC (2016). Patterns of taxonomic, phylogenetic diversity during a long-term succession of forest on the Loess Plateau, China: Insights into assembly process. Scientific Reports, 6, 27087. DOI: 10.1038/srep27087.

Chai YF, Yue M (2016). Research advances in plant community assembly mechanisms. Acta Ecologica Sinica, 36, 4557-4572. [柴永福, 岳明 (2016). 植物群落构建机制 研究进展. 生态学报, 36, 4557-4572.]

Chase JM (2003). Community assembly: When should history matter? Oecologia, 136, 489-498.

Che YD, Liu MX, Li LR, Jiao J, Xiao W (2017). Exploring the community assembly of subalpine meadow communities based on functional traits and community phylogeny. Chinese Journal of Plant Ecology, 41, 1157-1167. [车应弟, 刘旻霞, 李俐蓉, 焦骄, 肖卫 (2017). 基于功能性状及 系统发育的亚高寒草甸群落构建. 植物生态学报, 41 , 1157-1167.]

Faith DP (1992). Conservation evaluation and phylogenetic diversity. Biological Conservation, 61, 1-10.

Fang S, Yuan ZQ, Lin F, Ye J, Hao ZQ, Wang XG (2014). Functional and phylogenetic structures of woody plants in broad-leaved Korean pine mixed forest in Changbai Mountains, Jilin, China. Chinese Science Bulletin, 59, 2342-2348. [房帅, 原作强, 萄菲, 叶吉, 郝占庆, 王绪 高 (2014). 长白山阔叶红松林木本植物系统发育与功 能性状结构. 科学通报, 59, 2342-2348.]

Foster BL, Dickson TL, Murphy CA, Karel IS, Smith VH (2004). Propagule pools mediate community assembly and diversity-Ecosystem regulation along a grassland productivity gradient. Journal of Ecology, 92, 435-449.

Gong GQ, Huang ZL, Huang JX, Ye WH, Cao HL, Lian JY, Lin GJ (2011). How individual species structure the community in Dinghushan 20 ha forest plot? Ecology and Environmental Sciences, 20, 991-995. [宫贵权, 黄忠良, 黄 建雄, 叶万辉, 曹洪麟, 练琚愉, 林国俊 (2011). 鼎湖 山20公顷森林样地单个物种对群落的构建. 生态环境 学报, 20, 991-995.]

Grime JP (1998). Benefits of plant diversity to ecosystems: Immediate, filter and founder effects. Journal of Ecology, 86, 902-910.

Hodkinson ID, Coulson SJ, Webb NR (2003). Community assembly along proglacial chronosequences in the high Arctic: Vegetation and soil development in north-west Svalbard. Journal of Ecology, 91, 651-663.

Huang JX, Zhang J, Shen Y, Lian JY, Cao HL, Ye WH, Wu
LF, Bin Y (2014). Different relationships between temporal phylogenetic turnover and phylogenetic similarity and in two forests were detected by a new null model. PLOS ONE, 9, e95703. DOI: 10.1371/journal.pone.0095703.

Huang JX, Zheng FY, Mi XC (2010). Influence of environmental factors on phylogenetic structure at multiple spatial scales in an evergreen broad-leaved forest of China. Chinese Journal of Plant Ecology, 34, 309-315. [黄建雄, 郑 凤英, 米湘成 (2010). 不同尺度上环境因子对常绿阔叶 林群落的谱系结构的影响. 植物生态学报, 34, 309-315.]

Hubbell SP (2001). The Unified Neutral Theory of Biodiversity and Biogeography. Princeton University Press, Princeton. 340-348.

Hulshof CM, Violle C, Spasojevic MJ, McGill B, Damschen E, Harrison S, Enquist BJ (2013). Intra-specific and inter-specific variation in specific leaf area reveal the importance of abiotic and biotic drivers of species diversity across elevation and latitude. Journal of Vegetation Science, 24, 921-931.

Jia P, Du GZ (2014). Measuring functional and phylogenetic diversity in community ecology. Chinese Bulletin of Life Sciences, 26, 153-157. [贾鹏, 杜国祯 (2014). 生态学的 多样性指数: 功能与系统发育. 生命科学, 26, 153-157.]

Jiang XY, Liang LF, Bi RC, Yan M (2016). Spatial pattern of phylogenetic structure of plant community in Shanxi Huoshan mountain. Acta Botanica Boreali-Occidentalia Sinica, 36, 2505-2512. [姜晓燕, 梁林峰, 毕润成, 间明 (2016). 山西霍山植物群落谱系结构的空间格局. 西北 植物学报, 36, 2505-2512.]

Kelly CK, Bowler MG, Pybus O, Harvey PH (2008). Phylogeny, niches, and relative abundance in natural communities. Ecology, 89, 962-970.

Kraft NB, Cornwell WK, Webb CO, Ackerly DD (2007). Trait evolution, community assembly, and the phylogenetic structure of ecological communities. The American Naturalist, 170, 271-283.

Kylafis G, Loreau M (2011). Niche construction in the light of niche theory. Ecology Letters, 14, 82-90.

Lessard JP, Fordyce JA, Gotelli NJ, Sanders NJ (2009). Invasive ants alter the phylogenetic structure of ant communities. Ecology, 90, 2664-2669.

Lu MM, Huang XC, Ci XQ, Yang GP, Li J (2014). Phylogenetic community structure of subtropical forests along elevational gradients in Ailao Mountains of southwest China. Biodiversity Science, 22, 438-448. [卢孟孟, 黄小 翠, 慈秀芹, 杨国平, 李捷 (2014). 沿海拔梯度变化的 哀牢山亚热带森林群落系统发育结构. 生物多样性, 22 , 438-448.]

Mayfield MM, Levine JM (2010). Opposing effects of competitive exclusion on the phylogenetic structure of communities. Ecology Letters, 13, 1085-1093. 
Mori AS, Shiono T, Koide D, Kitagawa R, Ota AT, Mizumachi E (2013). Community assembly processes shape an altitudinal gradient of forest biodiversity. Global Ecology and Biogeography, 22, 878-888.

Niu HY, Wang ZF, Lian JY, Ye WH, Shen H (2011). New progress in community assembly: Community phylogenetic structure combining evolution and ecology. Biodiversity Science, 19, 275-283. [牛红玉, 王峥峰, 练琚愉, 叶万辉, 沈浩 (2011). 群落构建研究的新进展: 进化和 生态相结合的群落谱系结构研究. 生物多样性, 19, 275-283.]

Park DS, Potter D (2015). Why close relatives make bad neighbours: Phylogenetic conservatism in niche preferences and dispersal disproves Darwin's naturalization hypothesis in the thistle tribe. Molecular Ecology, 24, 3181-3193.

Pottier J, Dubuis A, Pellissier L, Maiorano L, Rossier L, Randin CF, Vittoz P, Guisan A (2013). The accuracy of plant assemblage prediction from species distribution models varies along environmental gradients. Global Ecology and Biogeography, 22, 52-63.

Purschke O, Schmid BC, Sykes MT, Poschlod P, Michalski SG, Durka W, Kühn I, Winter M, Prentice HC (2013). Contrasting changes in taxonomic, phylogenetic and functional diversity during a long-term succession: Insights into assembly processes. Journal of Ecology, 101, 857-866.

Qian H, Hao ZQ, Zhang J (2014). Phylogenetic structure and phylogenetic diversity of angiosperm assemblages in forests along an elevational gradient in Changbaishan, China. Journal of Plant Ecology, 7, 154-165.

Qiao XJ, Jabot F, Tang ZY, Jiang MX, Fang JY (2015). A latitudinal gradient in tree community assembly processes evidenced in Chinese forests. Global Ecology and Biogeography, 24, 314-323.

Swenson NG, Enquist BJ, Thompson J, Zimmerman JK (2007). The influence of spatial and size scale on phylogenetic relatedness in tropical forest communities. Ecology, 88, 1770-1780.

Swenson NG, Erickson DL, Mi XC, Bourg NA, ForeroMontaña J, Ge XJ, Howe R, Lake JK, Liu XJ, Ma KP, Pei NC, Thompson J, Uriarte M, Wolf A, Wright SJ, Ye WH, Zhang JL, Zimmerman JK, Kress WJ (2012). Phylogenetic and functional alpha and beta diversity in temperate and tropical tree communities. Ecology, 93(Suppl.), S112-S125.

Tang ZY, Fang JY, Zhang L (2004). Patterns of woody plant species diversity along environmental gradients on Mt. Taibai, Qinling Mountains. Biodiversity Science, 12, 115-122. [唐志尧, 方精云, 张玲 (2004). 秦岭太白山 木本植物物种多样性的梯度格局及环境解释. 生物多 样性, 12, 115-122.]

Tucker CM, Cadotte MW, Carvalho SB, Davies TJ, Ferrier S, Fritz SA, Grenyer R, Helmus MR, Jin LS, Mooers AO, Pavoine S, Purschke O, Redding DW, Rosauer DF, Winter
M, Mazel F (2017). A guide to phylogenetic metrics for conservation, community ecology and macroecology. Biological Reviews, 92, 698-715.

Webb CO (2000). Exploring the phylogenetic structure of ecological communities: An example for rain forest trees. The American Naturalist, 156, 145-155.

Webb CO, Ackerly DD, McPeek MA, Donoghue MJ (2002). Phylogenies and community ecology. Annual Review of Ecology and Systematics, 33, 475-505.

Webb CO, Donoghue MJ (2005). Phylomatic: Tree assembly for applied phylogenetics. Molecular Ecology Notes, 5, 181-183.

Wehncke EV, Hubbell SP, Foster RB, Dalling JW (2003). Seed dispersal patterns produced by white-faced monkeys: Implications for the dispersal limitation of neotropical tree species. Journal of Ecology, 91, 677-685.

Wiens JJ, Graham CH (2005). Niche conservatism: Integrating evolution, ecology, and conservation biology. Annual Review of Ecology Evolution and Systematics, 36, 519-539.

Wikström N, Savolainen V, Chase MW (2001). Evolution of the angiosperms: Calibrating the family tree. The Proceedings of the Royal Society B, 268, 2211-2220.

Xu JS, Chai YF, Wang M, Dang H, Guo YX, Chen Y, Zhang CG, Li T, Zhang LX, Yue M (2018). Shifts in plant community assembly processes across growth forms along a habitat severity gradient: A Test of the plant functional trait approach. Frontiers in Plant Science, 9, 180. DOI: 10.3389/fpls.2018.00180.

Xu JS, Chen Y, Zhang LX, Chai YF, Wang M, Guo YX, Li T, Yue M (2017). Using phylogeny and functional traits for assessing community assembly along environmental gradients: A deterministic process driven by elevation. Ecology and Evolution, 7, 5056-5069.

Yang J, Lu MM, Cao M, Li J, Lin LX (2014). Phylogenetic and functional alpha and beta diversity in mid-mountain humid evergreen broad-leaved forest. Chinese Science Bulletin, 59，2349-2358. [杨洁，卢孟孟，曹敏，李捷，林露湘 (2014). 中山湿性常绿阔叶林系统发育和功能性状的 $\alpha$ 及 $\beta$ 多样性. 科学通报, 59, 2349-2358.]

Yang YC, Da LJ (2006). A brief review of studies on differentiation of vegetation pattern along a topographic gradient in hilly regions. Journal of Plant Ecology (Chinese Version), 30, 504-513. [杨永川, 达良俊 (2006). 丘陵地区 地形梯度上植被格局的分异研究概述. 植物生态学报, 30, 504-513.]

Yuan X, Ma KM, Wang D (2011). Explaining the abundance-distribution relationship of plant species with niche breadth and position in the Yellow River Delta. Acta Ecologica Sinica, 31，1955-1961. [袁秀, 马克明, 王德 (2011). 黄河三角洲植物生态位和生态幅对物种分布多度关系的解释. 生态学报, 31, 1955-1961.]

Zhang H, Gilbert B, Zhang XX, Zhou SR (2013). Community

www.plant-ecology.com 
assembly along a successional gradient in sub-alpine meadows of the Qinghai-Tibetan Plateau, China. Oikos, 122, 952-960.

Zhao MF, Xue F, Wang YH, Wang GY, Xing KX, Kang MY, Wang JL (2017). Phylogenetic structure and diversity of herbaceous communities in the conifer forests along an elevational gradient in Luya Mountain, Shanxi, China. Chinese Journal of Plant Ecology, 41, 707-715. [赵鸣飞, 薛峰, 王宇航, 王国义, 邢开雄, 康慕谊, 王菁兰
(2017). 山西芦芽山针叶林草本层群落谱系结构与多样 性的海拔格局. 植物生态学报, 41, 707-715.]

Zhou XG, Lu WK, Ye D, Wen YG. (2014). Assembly mechanism of forest community based on phylogeny and functional traits. Guangxi Sciences, 21, 525-533. [周晓果, 卢 文科, 叶铎, 温远光 (2014). 基于系统发育和功能性状 的森林群落构建机制. 广西科学, 21, 525-533.]

责任编委: 唐志尧 责任编辑: 李 敏 实习编辑: 赵 航

附录I 华北森林群落各样方中出现的物种及其所属科

Supplement I The species and its family in plots of forest community in North China

http://www.plant-ecology.com/fileup/1005-264X/PDF/cjpe.2018.0183-S1.pdf

附录II 华北森林群落样方间环境因子的典范对应分析(CCA)结果

Supplement II The result of canonical correspondence analysis (CCA) of environment factors of forest community in North China

http://www.plant-ecology.com/fileup/1005-264X/PDF/cjpe.2018.0183-S2.pdf 
许金石, 柴永福, 刘晓, 岳明, 郭圭金金, 康慕谊, 刘全儒, 郑成洋, 吉成均, 问明, 张峰, 高贤 明, 王仁卿, 石福臣, 张钦弟, 王茂 (2019). 华北区域环境梯度上阔叶林构建模式及分布成 因. 植物生态学报, 43, 732-741. DOI: 10.17521/cjpe.2018.0183

Xu JS, Chai YF, Liu X, Yue M, Guo YX, Kang MY, Liu QR, Zheng CY, Ji CJ, Yan M, Zhang F, Gao XM, Wang RQ, Shi FC, Zhang QD, Wang M (2019). Community assembly, diversity patterns and distributions of broad-leaved forests in North China. Chinese Journal of Plant Ecology, 43, 732-741. DOI: 10.17521/cjpe.2018.0183

http://www.plant-ecology.com/CN/10.17521/cjpe.2018.0183

附录I 华北森林群落各样方中出现的物种及其所属科

Supplement I The species and its family in plots of forest community in North China

\begin{tabular}{|c|c|c|}
\hline 物种名 & 拉丁名 & 所属科 \\
\hline Species & Latin name & Family \\
\hline 老鸹铃 & Styrax hemsleyanus & 安息香科 Styracaceae \\
\hline 野茉莉 & Styrax japonicus & \\
\hline 瓜木 & Alangium plataaifoliam & 八角枫科 Alangiaceae \\
\hline 短梗菝葜 & Smilax scobinicaulis & 百合科 Liliaceae \\
\hline 鞘柄菝葜 & Smilax stans & \\
\hline 托柄菝葜 & Smilax discotis & \\
\hline 侧柏 & Platycladus orientalis & 柏科 Cupressaceae \\
\hline 白背叶 & Mallotus apelta & 大戟科 Euphorbiaceae \\
\hline 雀儿舌头 & Leptopus chinenais & \\
\hline 白刺花 & Sophora davidii & 豆科 Leguminosae \\
\hline 刺槐 & Robinia pseudoacacia & \\
\hline 多花胡枝子 & Lespedeza floribunda & \\
\hline 杭子梢 & Campylotropis macrocarpa & \\
\hline 合欢 & Albizia julibrissin & \\
\hline 红花锦鸡儿 & Caragana rosea & \\
\hline 胡枝子 & Lespedeza bicolor & \\
\hline 黄檀 & Dalbergia hupeana & \\
\hline 绿叶胡枝子 & Lespedeza buergeri & \\
\hline 美丽胡枝子 & Lespedeza formosa & \\
\hline 山槐 & Albizia kalkora & \\
\hline 细梗胡枝子 & Lespedeza virgata & \\
\hline 长叶胡枝子 & Lespedeza caraganae & \\
\hline 杜鹃 & Rhododendron simsii & 杜鹃花科 Ericaceae \\
\hline 迎红杜鹃 & Rhododendron mucronulatum & \\
\hline 照山白 & Rhododendron micranthum & \\
\hline 扁担杆 & Grewia biloba & 椴树科 Tiliaceae \\
\hline 椴树 & Tilia tuan & \\
\hline 蒙椴 & Tilia mongolica & \\
\hline 小花扁担杆 & Grewia biloba var. parviflora & \\
\hline 小叶椴 & Tilia mongolica & \\
\hline 核桃 & Juglans regia & 胡桃科 Juglandaceae \\
\hline 核桃楸 & Juglans mandshurica & \\
\hline
\end{tabular}




\begin{tabular}{|c|c|c|}
\hline 物种名 & 拉丁名 & 所属科 \\
\hline Species & Latin name & Family \\
\hline 化香树 & Platycarya strobilacea & \\
\hline 牛奶子 & Elaeagnus umbellata & 胡颓子科 laeagnaceae \\
\hline 沙棘 & Hippophae rhamnoides & \\
\hline 大枝绣球 & Hydrangea gracilis & 虎耳草科 Saxifragaceae \\
\hline 东北茶蔍子 & Ribes mandshuricum & \\
\hline 东陵绣球 & Hydrangea bretschneideri & \\
\hline 钩齿淺疏 & Deutzia hamata & \\
\hline 瘤糖茶蔍子 & Ribes himalense var. verruculosum & \\
\hline 山梅花 & Philadelphus incanus & \\
\hline 太平花 & Philadelphus pekinensis & \\
\hline 小果茶蔍子 & Ribes vilmorinii & \\
\hline 小花溲疏 & Deutzia crassifolia var. pauciflora & \\
\hline 白桦 & Betula platyphylla & 华木科 Betulaceae \\
\hline 䊁皮华 & Betula utilis & \\
\hline 鹅耳枥 & Carpinus turczaninowii & \\
\hline 红桦 & Betula albosinensis & \\
\hline 毛榛 & Corylus mandshurica & \\
\hline 千金榆 & Carpinus cordata & \\
\hline 榛 & Corylus heterophylla & \\
\hline 牛鼻栓 & Fortunearia sinensis & 金缕梅科 Hamamelidaceae \\
\hline 华帚菊 & Pertya sinensis & 菊科 Composieae \\
\hline 蚂蚱腿子 & Myripnois dioica & \\
\hline 白栋 & Quercus fabri & 壳斗科 Fagaceae \\
\hline 板栗 & Castanea mollissima & \\
\hline 短柄枹栋 & Quercus serrata var. brevipetiolata & \\
\hline 槲柇 & Quercus aliena & \\
\hline 触树 & Quercus dentata & \\
\hline 辽东栋 & Quercus wutaishanica & \\
\hline 麻栋 & Quercus acutissima & \\
\hline 锐齿槲柇 & Quercus aliena var. acuteserrata & \\
\hline 栓皮栋 & Quercus variabilis & \\
\hline 臭椿 & Ailanthus altissima & 苦木科 Simaroubaceae \\
\hline 楝树 & Melia azedarach & 楝科 Meliaceae \\
\hline 杜柳 & Periploca sepium & 萝藦科 Asclepiadaceae \\
\hline 荆条 & Vitex negundo var. heterophylla & 马鞭草科 Verbenaceae \\
\hline 粗齿铁线莲 & Clematis argentilucida & 毛茛科 Ranunculaceae \\
\hline 多花木兰 & Magnolia multiflora & 木兰科 Magnoliaceae \\
\hline 白蜡 & Fraxinus chinensis & 木犀科 Oleaceae \\
\hline 暴马丁香 & Syringa reticulata var. amurensis & \\
\hline 北京丁香 & Syringa pekinensis & \\
\hline 丁香 & Syringa oblata & \\
\hline 花曲柳 & Fraxinus rhynchophylla & \\
\hline
\end{tabular}


10.17521/cjpe.2018.0183-S1

\begin{tabular}{|c|c|c|}
\hline 物种名 & 拉丁名 & 所属科 \\
\hline Species & Latin name & Family \\
\hline 连趐 & Forsythia suspensa & \\
\hline 毛丁香 & Syringa tomentella & \\
\hline 小叶白蜡 & Fraxinus bungeana & \\
\hline 葎叶蛇葡萄 & Ampelopsis humulifolia & 葡萄科 Vitaceae \\
\hline 掌叶蛇葡萄 & Ampelopsis delavayana & \\
\hline 黄连木 & Pistacia chinensis & 漆树科 Anacardiaceae \\
\hline 黄栌 & Cotinus coggygria & \\
\hline 漆 & Toxicodendron vernicifluum & \\
\hline 青赫杨 & Rhus potaninii & \\
\hline 盐肤木 & Rhus chinensis & \\
\hline 茶条槭 & Acer ginnala subsp. ginnala & 槭树科 Aceraceae \\
\hline 葛萝棫 & Acer grosseri var. grosseri & \\
\hline 鸡爪槭 & Acer palmatum var. palmatum & \\
\hline 青榨棫 & Acer davidii & \\
\hline 色木械 & Acer mono & \\
\hline 细裂棫 & Acer stenolobum & \\
\hline 细叶槭 & Acer leptophyllum & \\
\hline 元宝械 & Acer truncatum & \\
\hline 六月雪 & Serissa japonica & 茜草科 Rubiaceae \\
\hline 香果树 & Emmenopterys henryi & \\
\hline 白鹃梅 & Exochorda racemosa & 蓄薇科 Rosaceae \\
\hline 白叶莓 & Rubus innominatus & \\
\hline 北京花梑 & Sorbus discolor & \\
\hline 稠李 & Padus racemosa & \\
\hline 刺梨 & Rosa roxburghii & \\
\hline 豆梨 & Pyrus calleryana & \\
\hline 杜梨 & Pyrus betulaefolia & \\
\hline 复盆子 & Rubus idaeus & \\
\hline 甘肃山楂 & Crataegus kansuensis & \\
\hline 高粱泡 & Rubus lambertianus & \\
\hline 河南海棠 & Malus honanensis & \\
\hline 褐梨 & Pyrus phaeocarpa & \\
\hline 湖北山楂 & Crataegus hupehensis & \\
\hline 花楸 & Sorbus pohuashanensis & \\
\hline 华北绣线菊 & Spiraea fritschiana var. angulata & \\
\hline 华中山楂 & Crataegus wilsonii & \\
\hline 黄刺玫 & Rosa xanthina & \\
\hline 灰栒子 & Cotoneaster acutifolius var. villosulus & \\
\hline 麦李 & Cerasus glandulosa & \\
\hline 毛叶绣线菊 & Spiraea mollifolia & \\
\hline 茅莓 & Rubus parvifolius & \\
\hline 美蓄薇 & Rosa bella & \\
\hline
\end{tabular}


10.17521/cjpe.2018.0183-S1

\begin{tabular}{|c|c|c|}
\hline 物种名 & 拉丁名 & 所属科 \\
\hline Species & Latin name & Family \\
\hline 木梨 & Pyrus xerophila & \\
\hline 牛叠肚 & Rubus crataegifolius & \\
\hline 三裂绣线菊 & Spiraea trilobata & \\
\hline 山荆子 & Malus baccata & \\
\hline 山莓 & Rubus corchorifolius & \\
\hline 山桃 & Amygdalus davidiana & \\
\hline 山杏 & Armeniaca sibirica & \\
\hline 山楂 & Crataegus pinnatifida & \\
\hline 水栒子 & Cotoneaster submultiflorus & \\
\hline 土庄绣线菊 & Spiraea pubescens & \\
\hline 托叶樱桃 & Cerasus stipulacea & \\
\hline 微毛樱桃 & Cerasus clarofolia & \\
\hline 尾叶樱 & Cerasus dielsiana & \\
\hline 西北栒子 & Cotoneaster zabelii & \\
\hline 毛杏 & Armeniaca sibirica & \\
\hline 野蓄薇 & Rosa multiflora var. multiflora & \\
\hline 野山楂 & Crataegus cuneata & \\
\hline 华空木 & Stephanandra chinensis & \\
\hline 银露梅 & Potentilla glabra & \\
\hline 郁李 & Cerasus japonica & \\
\hline 长腺樱桃 & Cerasus claviculata & \\
\hline 北京忍冬 & Lonicera elisae & 忍冬科 Caprifoliaceae \\
\hline 刚毛忍冬 & Lonicera hispida & \\
\hline 黑果英蒾 & Viburnum melanocarpum & \\
\hline 华叶荚蒾 & Viburnum betulifolium & \\
\hline 鸡树条荚蒾 & Viburnum opulus var. calvescens & \\
\hline 接骨木 & Sambucus williamsii & \\
\hline 金花忍冬 & Lonicera chrysantha & \\
\hline 金银忍冬 & Lonicera maackii & \\
\hline 蓝靛果忍冬 & Lonicera caerulea var. edulis & \\
\hline 六道木 & Abelia biflora & \\
\hline 蒙古荚蒾 & Viburnum mongolicum & \\
\hline 盘叶忍冬 & Lonicera tragophylla & \\
\hline 忍冬 & Lonicera japonica & \\
\hline 陕西荚蒾 & Viburnum schensianum & \\
\hline 唐古特忍冬 & Lonicera tangutica & \\
\hline 五台忍冬 & Lonicera Kungana & \\
\hline 苦糖果 & Lonicera fragrantissima subsp. standishii & \\
\hline 粘毛忍冬 & Lonicera fargesii & \\
\hline 粗榧 & Cephalotaxus sinensis & 三尖杉科 Cephalotaxaceae \\
\hline 构树 & Broussonetia papyifera & 桑科 Moraceae \\
\hline 华桑 & Morus cathayana & \\
\hline
\end{tabular}




\begin{tabular}{|c|c|c|}
\hline 物种名 & 拉丁名 & 所属科 \\
\hline Species & Latin name & Family \\
\hline 鸡桑 & Morus australis & \\
\hline 蒙桑 & Morus mongolica & \\
\hline 桑 & Morus alba & \\
\hline 白檀 & Symplocos paniculata & 山矾科 Symplocaceae \\
\hline 黑椋子 & Swida hemsleyi & 山茱英科 Cornaceae \\
\hline 红瑞木 & Swida alba & \\
\hline 梾木 & Swida macrophpla & \\
\hline 毛梾 & Swida walteri & \\
\hline 四照花 & Dendrobenthamia japonica var. chinensis & \\
\hline 沙梾 & Swida bretschneideri & \\
\hline 君迁子 & Diospyros lotus & 柿树科 Ebenaceae \\
\hline 油柿 & Diospyros oleifera & \\
\hline 大绿鼠李 & Rhamnus utilis & 鼠李科 Rhamnaceae \\
\hline 刺鼠李 & Rhamnus dumetorum & \\
\hline 鼠李 & Rhamnus davurica & \\
\hline 酸東 & Ziziphus jujuba var. spinosa & \\
\hline 小叶鼠李 & Rhamnus parvifolia & \\
\hline 白皮松 & Pinus bungeana & 松科 Pinaceae \\
\hline 赤松 & Pinus densiflora & \\
\hline 臭冷杉 & Abies nephrolepis & \\
\hline 黑松 & Pinus thunbergii & \\
\hline 华北落叶松 & Larix principisrupprechtii & \\
\hline 华山松 & Pinus armandi & \\
\hline 马尾松 & Pinus massoniana & \\
\hline 青扞 & Picea wilsonii & \\
\hline 油松 & Pinus tabulaeformis var. mukdensis & \\
\hline 黄心子 & Euonymus macropterus & 卫矛科 Celastraceae \\
\hline 南蛇藤 & Celastrus orbiculatus & \\
\hline 栓翅卫矛 & Euonymus phellomanus & \\
\hline 卫矛 & Euonymus alatus & \\
\hline 奕树 & Koelreuteria paniculata & 无患子科 Sapindaceae \\
\hline 梧桐 & Firmiana platanifolia & 梧桐科 Sterculiaceae \\
\hline 刺楸 & Kalopanax septemlobus & 五加科 Araliaceae \\
\hline 黄芦木 & Berberis amurensis & 小檗科 Berberidaceae \\
\hline 齿叶黄花柳 & Salix sinica var. dentata & \\
\hline 黄花柳 & Salix caprea & \\
\hline 秦岭柳 & Salix alfredi & \\
\hline 山柳 & Salix pseudotangii & \\
\hline 山杨 & Populus davidiana & \\
\hline 大果榆 & Ulmus macrocarpa & 榆科 Ulmaceae \\
\hline 大叶朴 & Celtis koraiensis & \\
\hline 黄果朴 & Celiis labilis & \\
\hline
\end{tabular}


10.17521/cjpe.2018.0183-S1

\begin{tabular}{|c|c|c|}
\hline 物种名 & 拉丁名 & 所属科 \\
\hline Species & Latin name & Family \\
\hline 旱榆 & Ulmus glaucescens & \\
\hline 朴 & Celtis sinensis & \\
\hline 脱皮榆 & Ulmus lamellosa & \\
\hline 小果朴 & Celtis cerasifera & \\
\hline 小叶朴 & Celtis bungeana & \\
\hline 榆树 & Ulmus pumila & \\
\hline 臭檀 & Evodia daniellii & 芸香科 Rutaceae \\
\hline 吴茱英 & Evodia rutaecarpa & \\
\hline 野花椒 & Zanthoxylum simulans & \\
\hline 绿叶甘價 & Lindera fruticosa var. fruticosa & 樟科 Lauraceae \\
\hline 三桠乌药 & Lindera obtusiloba & \\
\hline 山胡椒 & Lindera glauca & \\
\hline 棕榈 & Trachycarpus fortunei & 棕㭣科Palmae \\
\hline
\end{tabular}


许金石, 柴永福, 刘晓, 岳明, 郭圭金金, 康慕谊, 刘全儒, 郑成洋, 吉成均, 问明, 张峰, 高贤 明, 王仁卿, 石福臣, 张钦弟, 王茂 (2019). 华北区域环境梯度上阔叶林构建模式及分布成 因. 植物生态学报, 43, 732-741. DOI: 10.17521/cjpe.2018.0183

Xu JS, Chai YF, Liu X, Yue M, Guo YX, Kang MY, Liu QR, Zheng CY, Ji C J, Yan M, Zhang F, Gao XM, Wang RQ, Shi FC, Zhang QD, Wang M (2019). Community assembly, diversity patterns and distributions of broad-leaved forests in North China. Chinese Journal of Plant Ecology, 43, 732-741. DOI: 10.17521/cjpe.2018.0183

http://www.plant-ecology.com/CN/10.17521/cjpe.2018.0183

附录II 华北森林群落样方间环境因子的典范对应分析(CCA)结果 Supplement II The result of canonical correspondence analysis (CCA) of environment factors of forest community in North China

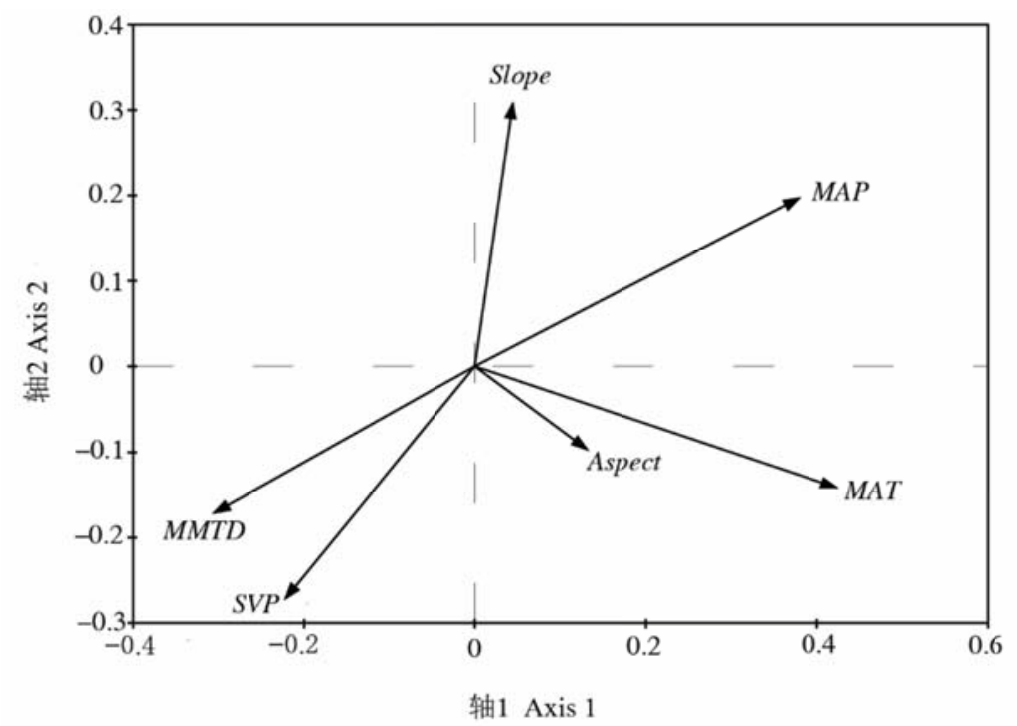

图中箭头的长度代表该因子对典范轴的解释程度, 箭头间的夹角代表因子间的相关性。Aspect, 坡向; MAP, 年降水量; $M A T$, 年平均气温; $M M T D$, 月平均气温极差; Slope, 坡度; SVP, 降水季节变化量。

The length of the arrows represents the degree of explanation of the factor to the canonical axis, and the angle between the arrows represents the correlation among the factors. Aspect, aspect of plot; MAP, annual average precipitation; MAT, annual average temperature; MMTD, monthly mean temperature difference; Slope, slope of plot; SVP, seasonal precipitation variation. 